\title{
FIRST REPORT OF A JOURNEY IN PISIDIA, LYCAONIA, AND PAMPHYLIA.
}

\section{PART III.}

Continued from Vol. XXII, p. 376.

\section{E.-Khatyn Serai ( $\Lambda \dot{\sigma} \sigma \tau \rho a$ ) and Neighbourhood.}

We were at Khatyn Serai for four days, arriving on the fourth day of July, 1901, and leaving on the seventh. Our road from Konia lay through Baiyat, where we copied the following inscription.

\section{Baiyat.}

No. 150.-W.M.R., H.S.C., G.A.W.

OYATIAN
UAPKEAAAN
AI QYAAI
THCKOAW
NEIAC
$\mu$

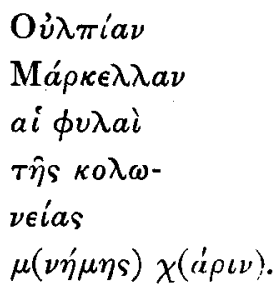

The length of our stay at Khatyn Serai enabled us to become acquainted with a good number of inscriptions. Besides verifying almost all the inscriptions already published from Professor Sterrett's copies, or from Professor Ramsay's earlier ones (cf. W.E. pp. 242 ff.; C.I.L. vol. iii. pp. 1239 and 2061), we heard of and copied twenty-four new inseriptions, ten of which are in Latin and one bilingual. We were also able to make some examination of Zoldera, the site of the ancient city, which lies rather more than a mile N.W. of the village.

The inscriptions are most conveniently considered according to the language in which they are written; for if they were found on the site of the modern village, they were in all probability carried thither from Zoldera. 


\section{Latin Inscriptions.}

151.-In a hut on the south side of Zoldera. W.M.R.

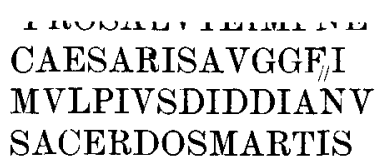

$$
\begin{aligned}
& \text { Pro salute Imp(eratoris) Ne[rvae } \\
& \text { Caesaris Aug(usti) Ger[manici } \\
& \text { M(arcus) Ulpius Diddianu[s, } \\
& \text { Sacerdos Martis. }
\end{aligned}
$$

Some of the inscription, which has been published from our copies in the C.I.L. (vol. iii. No. 14400), has been lost on the right. The date of the inscription is Oct. 97-Jan. 98. For the name Ulpius at Lystra cf. our No. 150 and W.E. No. 254; for Diddianus ef. C.I.L. vol. iii. No. 6627 (the inscription is at Coptos, but C. Didius was from Ancyra), and L. Didius Marinus (No. 6753, Ancyra).

No. 152.-Western Cemetery. W.M.R. 1882 and 1903.

L.OCT.MODESTVS
OMNIBVS MVNE
RIBVS FVNCTVS
SIBI VIVVS PO
V T $\diamond \diamond$

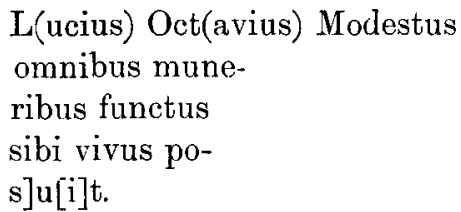

Between lines 1 and 2 is a horseman galloping spear in hand. Cf. B.C.H. 1883, p. 316 ; C.I.L. vol, iii., No. 6788.

No. 153.-W.M.R., H.S.C., G.A.W.

$$
\begin{aligned}
& \text { LENNIVSRVFVS · ENNIORVFOPATRIET } \times \\
& \text { ENN } \\
& \text { RIAESORORIETENNIO. } \\
& \text { L(ucius) Ennius Rufus Ennio Rufo patri et } \\
& \text { Enn[io fratri et En]niae sorori et Ennio } \\
& \text { R[....... et s]ibi et Enniae matri vi[vis }
\end{aligned}
$$

The letters are small and well formed; the surface of the stone is much worn. This is C.I.L. vol. iii. No. 12141. G.A.W.

No. 154.-Zoldera, in a hut between the tepé and the Ayasma. H.S.C.

\section{LOLLIAE TERVNOAE SOCR $\Lambda \in \Lambda$ MICISSIMAE \\ PANNIVS // ROCVLA \\ NVY MEMORIAE \\ CAVSA}

Lolli[a]e Secundae socr[a]e [a]micissimae $\mathrm{P}$ (ublius) Annius [P]roculanus memoriae causa.

For Annius cf. No. 155 and perhaps No. 156. This is C.I.L. vol. iii. No. $14400 f$. 
No. 155.-W.M.R.

$\begin{array}{ll}\text { QIAITILIONEPOTI } & \text { Q(uinto) Laitilio Nepoti } \\ \text { ANNIA VETTIAVXOR } & \text { Annia Vettia uxor } \\ \text { EIVSMEMORIAICAVSA } & \text { eius memoriai cansa } \\ \text { EI SIBI RESTITVIT } & \text { et sibi restituit. }\end{array}$

This is C.I.L. vol. iii. No. $14400 e$.

No. 156.-W.M.R., H.S.C., G.A.W.

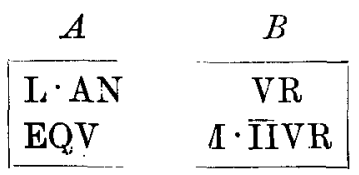

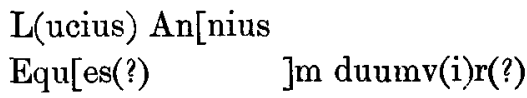

The stones $A$ and $B$ are, the one in the eastern, the other in the western bridge. They are similar in character and the letters are of the same size, five inches high, and are finely and deeply cut; they belong to the early Imperial period. Apparently both are complete on the three sides indicated; there is no clue to the extent of the gap between them. The interpretation of VR as vir is uncertain. This is C.I.L. vol. iii. No. $14400 \mathrm{~b}$ (cf. No. 6797 and B.C.H. 1883, p. 317).

No. 15T.-W.M.R.

$\checkmark \mathrm{A}$

$J \cdot$ PROBI

Probi-

$\mathrm{NO} \cdot \mathrm{M} \cdot \mathrm{C} \cdot$

no m(emoriae) c(ausa)

Complete at bottom and on right.

No. 158.—On a pedestal ; slightly ornate; much broken. W.M.R.

$\begin{array}{cc}\text { AQVI } & \text { Aqui[lam legatum Augusti pro } \\ \text { PRAE } & \text { prae[tore } \\ \text { XII } & \text { xii[tribus }\end{array}$

Good early Imperial lettering. Complete except on right and possibly at top. If our restoration be correct, there must have been a line above our first line with the full name of Cornutus Aquila, who was governor of Galatia in B.C. 6 (cf. our No. 7, 11, and 12). The monument must have been erected at the time of the foundation of the colony. For the tribes of Lystra cf. our No. 150. This is C.I.T. No. $14400 d$. 
No. 159.-On a lion. W.M.R.

///RVFVSETLV Rufus et Lu[cius

Complete on right. This is C.I.L. $14400 \mathrm{~h}$ (cf. 6796 and B.C.H. 1883, p. 317).

No. 160.-W.M.R.

\begin{tabular}{|c|c|}
\hline $\mathrm{HUS} \cdot \mathrm{SOC} \cdot \mathrm{P} / / \| \pi / / / \mathrm{LIN}$ & ]hus Soc. P[au]lin[us et uxor \\
\hline ILIAGRAPTE & eius Pup]ilia Grapte [P]upilia[e \\
\hline$\checkmark:$ AE MONOMENTV/// & En]n[i]ae monomentu[m \\
\hline SV & F]il[iae] \\
\hline
\end{tabular}
and 5 .

Complete at bottom only. There is a broad blank space between lines 4

In addition to these inscriptions, seven (Nos. 242-248) are given by Sterrett on pp. 142-145 of the Wolfe Expeclition. We examined all. With regard to No. 242, I need only here ${ }^{1}$ call attention to the spelling Lustra which is found on coins and in Latin inscriptions of the colony. In No. 243, the transcription is correct. No. 244 should read

$\begin{array}{cl}\text { NCHARE } & \text { A]nchare- } \\ \text { NASECVN } & \text { na Secun[da } \\ \text { ILA } \Lambda \Lambda & \text { L(ucio) Am[ }\end{array}$

The symbols at the end of the third line are very uncertain-perhaps XL annorum.

In No. 245, delete the second $\mathrm{P}$ in line 2.

In No. 246, the first line appears to be IsIミAI. In line 5 the first word is SVIS, but the second is apparently IRPESIS, the first I being very uncertain. $\quad \mathbf{P}$ should perhaps be $\mathbf{R}$. We could not read PRAEDIS, which Mommsen suggested. CAVSAE is the last word, an engraver's error for CAVSA. Lines 4, 5, and 6 are complete on the right.

In No. 247, we have no record of any point in lines 1 and 2 . There is an erasure after the $\mathrm{O}$ in line 4 . The first $\mathrm{F}$ in line 5 should be a $\mathrm{P}$.

In No. 248. The copy in the C.I.L. (vol. iii., No. 6791) is right, where it disag rees with Sterrett. The first letter of line 2 is $\Lambda$ not $\mathbf{M}$.

\footnotetext{
I See p. 123.
} 
Bilingual Inscription.

No. 164.-W.M.R., H.S.C., G.A.W.

\section{$\therefore \quad$ II \\ IROEIVYM \\ EM $C \operatorname{Lr} A$ \\ ATINNIAKAE \\ OTATPAEAY}

TH ZWCA KAI

OTIWKOCM $\omega$

AN $\triangle P I$ AYTHC

MNHMHC

XAPIN
[Atinnia Cleopatra sibi

viva et $\mathrm{Opi}$ -

-o Cosmo] v-

iro eius $\mathrm{m}$.

em[oriae] c[a]ussa

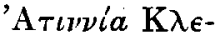

oтátpa éav-

$\tau \hat{\eta} \zeta \hat{\omega} \sigma a \kappa a i$

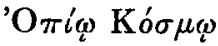

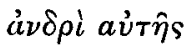

$\mu \nu \eta \dot{\mu} \eta \mathrm{s}$

$\chi^{a ́ \rho \iota \nu}$

This is C.I.L. 14400d.

Greek Inscriptions.

No. 162,-W.M.R.

$$
\begin{aligned}
& \Lambda E I O Y I N E I \omega \\
& \text { ГAIWKAI } \phi \wedge \wedge \\
& \text { YIAOQEANI } \\
& \Lambda E I \text { OYINEIOI } \\
& \text { o } \phi \in \Lambda \Lambda I O C K / / / I \\
& \text { WCIOEAГO } \\
& \mathrm{NEICI}
\end{aligned}
$$

No. 163.-W.M.R.

$$
\begin{aligned}
& \text { ANECTHCE } \\
& \text { BABW } \triangle I Y \\
& \text { NHAYTOY } \\
& \text { MNHMHC XAPIN }
\end{aligned}
$$

$$
\begin{aligned}
& \Lambda \in \iota 0 v \iota \nu \in i \omega \\
& \Gamma a i \omega \kappa a i . \Phi \lambda[a- \\
& \text { o]vía :O } \phi \epsilon \lambda \lambda i[a \\
& \text { Aelovínelo }
\end{aligned}
$$

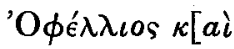

$$
\begin{aligned}
& \Delta] \omega \sigma \iota \theta \text { éa yo- } \\
& \nu \in \hat{\imath} \sigma \iota
\end{aligned}
$$

Relief with two figures above the inscription. There must also have been a line containing the husband's name above the relief.

The name $\mathrm{B} a \beta[\omega]$ occurs in C.I.G. 4142 (Ocuus, Ogur, or Ogut in Galatia, nine miles from Amasia on the road to Ancyra). 
No. 164.-W.M.R.

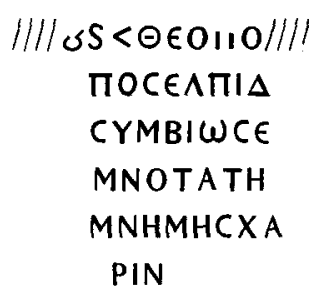

No. 165.-W.M.R., H.S.C,

\begin{tabular}{|c|c|}
\hline OYA $\triangle E P I O C$ & Oủa入épıos \\
\hline$Z W C I M O C$ & $Z \omega \dot{\sigma} \iota \mu \rho \varsigma$ \\
\hline $\mathrm{Z} \omega \mathrm{CIMH} \Delta \mathrm{I}$ & $Z \omega \sigma i \mu \eta \delta i$ \\
\hline OYTATPI & $\theta v \gamma a \tau \rho i$ \\
\hline
\end{tabular}

Below the inscription are two small arches containing reliefs.

No. 166.-W.M.R., H.S.C.

\begin{tabular}{|c|c|}
\hline AГAOHMEPOCKH & 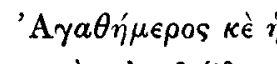 \\
\hline ГYNHAYTOYZW & $\gamma \nu \nu \grave{\eta} a \dot{\tau} \tau o \hat{v} \zeta \hat{\omega}-$ \\
\hline NTECTEKNOIC & 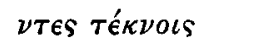 \\
\hline ГАYKYTATOIC & 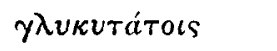 \\
\hline$M$ & $\mu\left[\nu \eta^{\prime} \mu \eta s \chi^{a ́} \rho \iota \nu\right.$ \\
\hline
\end{tabular}

No. 167.-W.M.R.

\begin{tabular}{|c|c|}
\hline АҮРНАIOC & A] $\dot{v} \rho \eta^{\prime} \lambda \iota s$ \\
\hline AONTEINOC & $\Lambda o \nu \gamma \varepsilon \hat{\imath} \nu \circ$ \\
\hline CTPATIWT & $\sigma \tau \rho a \tau \iota \dot{\tau} \tau-$ \\
\hline HCA & $\eta s \lambda \epsilon \gamma[\epsilon \hat{\omega} \nu \circ s$ \\
\hline
\end{tabular}

No. 168.-W.M.R., H.S.C., G.A.W.

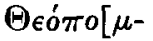

$$
\begin{aligned}
& \pi \circ \text { ' } \mathrm{E} \lambda \pi i \delta[\iota \\
& \sigma v \mu \beta i \omega \sigma \epsilon-
\end{aligned}
$$

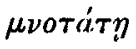

$$
\begin{aligned}
& \mu \nu \eta ́ \mu \eta s \chi^{a ́-} \\
& \rho \ell \nu .
\end{aligned}
$$

$\mu\left[\nu \eta \mu \eta s \chi^{a} \rho\right.$
No. 168.-W.M.R, H.S.C., G.A.W.

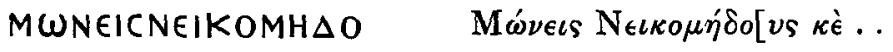

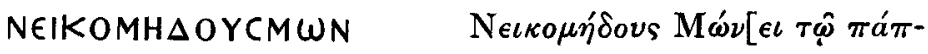

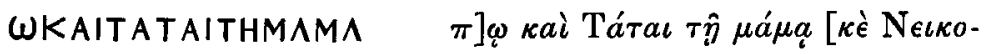

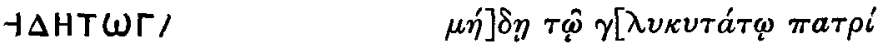

The stone now measures 15 inches in width. Above the inscription is a triangular pediment, containing the representation of an eagle. This fixes the centre of the stone, which was apparently originally 22 inches in width, and contained 5 or 6 letters to the right of those which still remain. The inscription is not complete at the foot. A short name stood at the end of line 1. 
No. 169.-W.M.R.

\author{
LEl, \\ LEINIO, \\ LMAKAPI \\ $\triangle E H E M O Y N$ \\ ATOYC $\triangle I Z Z$ \\ EMEUNTOETEPL \\ PANIOIOTIANINK
}

This is a fragment of a metrical epitaph.

No. 170.-On a very large block of building stone. W.M.R.

$$
\text { MPOK } \Lambda \text { OYTITIN } / / / /
$$

$\Pi \rho o ́ \kappa \lambda o \nu \mathrm{T} \iota \tau \iota \nu[\iota a \nu o \hat{v}$

Complete to left. Large good letters.

No. 171.-In the fountain. W.M.R., H.S.C., G.A.W.

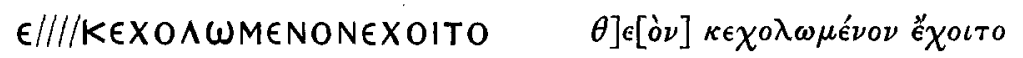

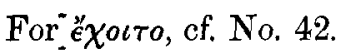

\begin{tabular}{|c|c|}
\hline $\mathbb{K A A C C}$ & $\left.{ }^{\prime} \mathrm{H} \rho a\right] \kappa \lambda \hat{\alpha} \varsigma$ \\
\hline$\triangle O M N A$ & $\kappa a i] \Delta o ́ \mu \nu a$ \\
\hline$\triangle O P K A C$ & $\kappa a i] \Delta o \rho \kappa a ̀ s$ \\
\hline ГATHP & $\theta v] \gamma a ́ t \eta \rho[\kappa a i$ \\
\hline YIOIE & vioi \\
\hline$M N H M E 1$ & $\mu \nu \eta \mu \epsilon \hat{\imath}-$ \\
\hline$N Z \Omega N T E C$ & $o] \nu_{2} \zeta \hat{\omega} \nu \tau \epsilon \varsigma$ \\
\hline$A T \in C K E Y$ & $\kappa] a \tau \epsilon \sigma \kappa \epsilon v^{\prime}$ \\
\hline A ANHAY & $a \sigma] a \nu$ \\
\hline $\begin{array}{l}\text { T } \\
I K A C \\
\| 11 K\end{array}$ & \\
\hline
\end{tabular}

No. 172.-W.M.R.

\begin{tabular}{|c|c|}
\hline AONTEINC/III & $\Lambda o \nu \gamma \in \hat{\imath} \nu 0[\mathrm{~s}$ \\
\hline$A \lambda \lambda$ IOY & 'A $\lambda \lambda[\iota a \nu] \circ \hat{v}$ \\
\hline $\begin{array}{c}\text { Horseman } \\
\text { right. }\end{array}$ & \\
\hline$\Pi \lambda \circ Y$ & $\Pi \lambda \circ v^{\prime}[\tau \omega \nu \iota$ \\
\hline EYXH & $\epsilon \dot{v} \chi \chi^{\prime}[\nu$ \\
\hline
\end{tabular}

No, 173.-W.M.R., H.S.C., G.A.W.

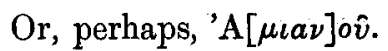


The Greek inscriptions (Nos. 249-255) in Sterrett occupy pp. 145-148 in the Wolfe Expedition. The following corrections should be made.

St. No. 249, line 1, the two upright strokes of the $\mathrm{N}$ of á $\nu \dot{\varepsilon} \sigma \tau \eta \sigma \epsilon \nu$ are legible; line $3, K$ can be read at the beginning; $T I$ should be $\Pi$, i.e.

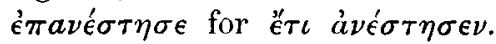

St. No. 250.-Whis inscription may be restored as follows:-

$$
\begin{aligned}
& \text { 'A. } \Sigma \epsilon[\iota \sigma \ldots \sigma] \omega \nu \kappa \grave{\epsilon} \text { 'A. Máркоs } \\
& \kappa \grave{~ ' A . ~ K a \pi i ́ t \omega \nu ~ v i o i ~ a v ่ t o v ̂ ~ \kappa e ̀ ~}
\end{aligned}
$$

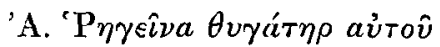

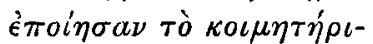

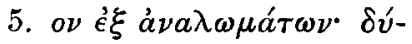

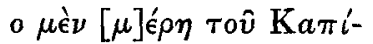

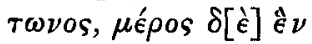

$$
\begin{aligned}
& \text { Joıs } a \dot{\delta} \in \lambda-
\end{aligned}
$$

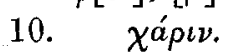

$$
\begin{aligned}
& \phi[o \hat{\imath}] \mathrm{s}[\mu] \nu \eta^{\prime} \mu \eta \mathrm{s}
\end{aligned}
$$

It was copied by Professor Ramsay, in 1882 and 1901: in $1901 \mathrm{Mr}$. Wathen and I were with him. In line 1, the letters placed between brackets are broken, and uncertain, but Sterrett's restoration $\Sigma \in[\pi . K a \pi i] \tau \omega \nu$ is wrong. In line 2 , the punctuation mark after $A$ is taken for an $I$. In line 5 , the

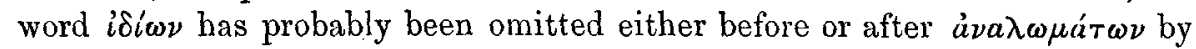
a slip of the engraver. In line 9 a symbol like $\times$ after the first $c$ must be a punctuation mark.

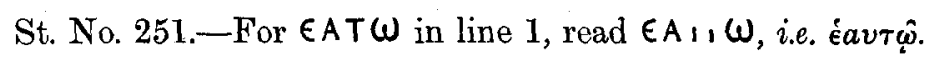

St. No. 252.-Read and restore as follows:

$$
\begin{aligned}
& \text { คYPHOEOAW } \\
& \text { C } \Delta I \text { YNTHIL } \\
& \text { HOYГI TPITAY }
\end{aligned}
$$

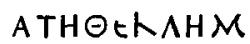

$$
\begin{aligned}
& M H \text { /PIN }
\end{aligned}
$$

There is a cross above the inscription. The inscription is complete on the left.

St. No. 253.-Read and restore as follows :

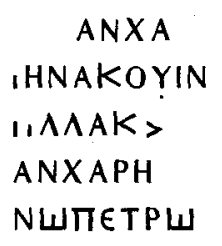

\author{
'A $\nu \chi \alpha-$

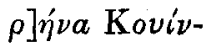 \\ $\tau \iota] \lambda \lambda a \mathrm{~K}(o \iota \imath \tau \omega)$ \\ 'A $\nu \chi a \rho \eta^{-}$ \\ $\nu \omega \Pi$ II $е т \rho \omega-$
}


FIRST REPORT OF A JOURNEY IN PISIDIA, ETC.
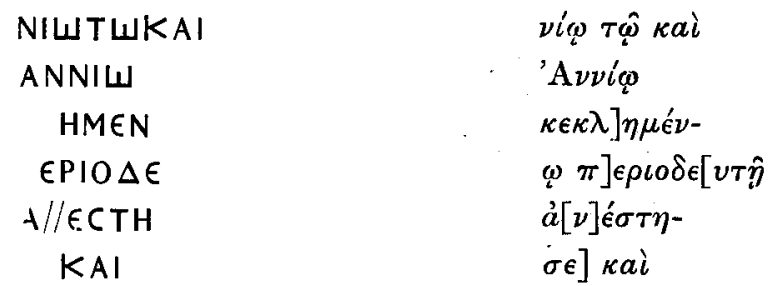

St. No. 255.-Restore 'I $\sigma \tau \eta^{\prime} \lambda \lambda \eta \Pi$ П $a \pi \pi \hat{a} \delta o s$.

Concerning Sterrett's inscriptions from Giömse (Nos. 266-268) we have nothing to say except to suggest that lines 9 and 10 of No. 267 should be restored thus :

$$
\begin{aligned}
& \kappa a i \gamma] o \nu[\varepsilon \hat{v}- \\
& \sigma \iota \nu
\end{aligned}
$$

Nos. 261-263 of Sterrett are republished from copies by Prof. Ramsay in C.I.L. vol. iii., No. 12215, with a complete text and the name Col. Lustrensium. Prof. Ramsay also sends me the following inscription :-

\begin{tabular}{|c|c|}
\hline MAPKOCA & $\mathrm{M} a \dot{\rho} \kappa o s^{\prime} \mathrm{A}\left[\tau \iota \lambda_{\iota}-(?)\right.$ \\
\hline OCAONTO & os $\Lambda o ́ \nu \gamma o[s \Phi \lambda-$ \\
\hline AYIAMAA & $\underset{\operatorname{avia}}{\prime} \mathbf{M} a \lambda[\lambda$ \\
\hline NAI ..C & $v] \nu a \iota[\kappa i]_{-}^{-} \hat{\epsilon}[a$ \\
\hline
\end{tabular}

Sari Kyz.-W.M.R.

The inscription is not complete on the right. Sari Kyz is a mile and a half north of Zoldera.

\section{Zoldera.}

The time which we had at our disposal enabled us to make some attempt at examining the site. Regular excavations were out of the question, not only because we were not provided with the necessary authority, but also because both time and funds for such research would have failed us. It was possible, however, to make a rough sketch of the site (Fig. 1), which besides serving an immediate purpose may prove of use to future explorers. The sketch together with a photograph of the tepé, taken from the south-east and shewing the inscribed pillar, is given on p. 121 (Figs. 1 and 2). The letter $A$ on the sketch marks the foundations of a small church $;^{2} B B B$ marks the course suggested along the side of the tepe for the road from Iconium. $C^{Y}$ is the spot pointed out to us as the site of the gate. $D$ marks the Ayasma described in Ramsay's The Church in the Roman Empire, p. 50, and $E$ the inscribed pillar. 

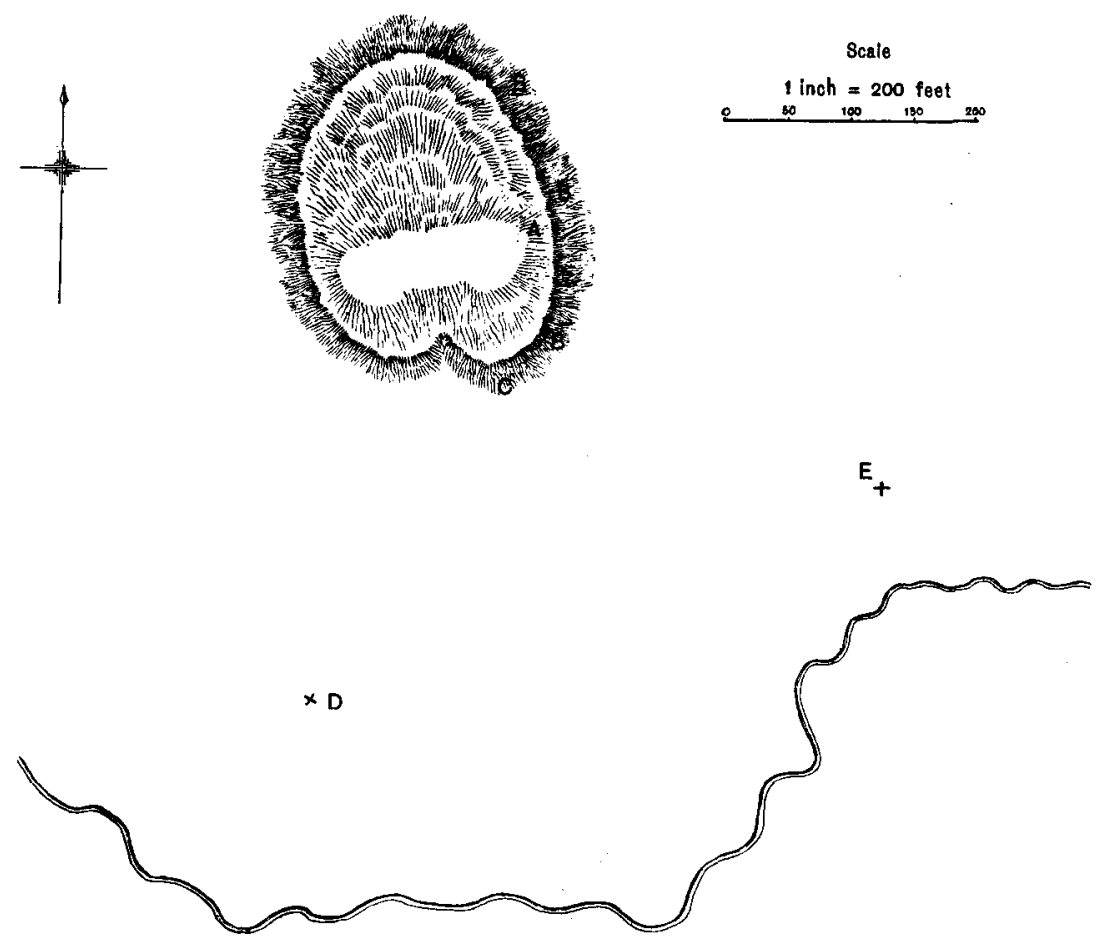

Fig. 1-Shetch-Plan of Site of Listra.

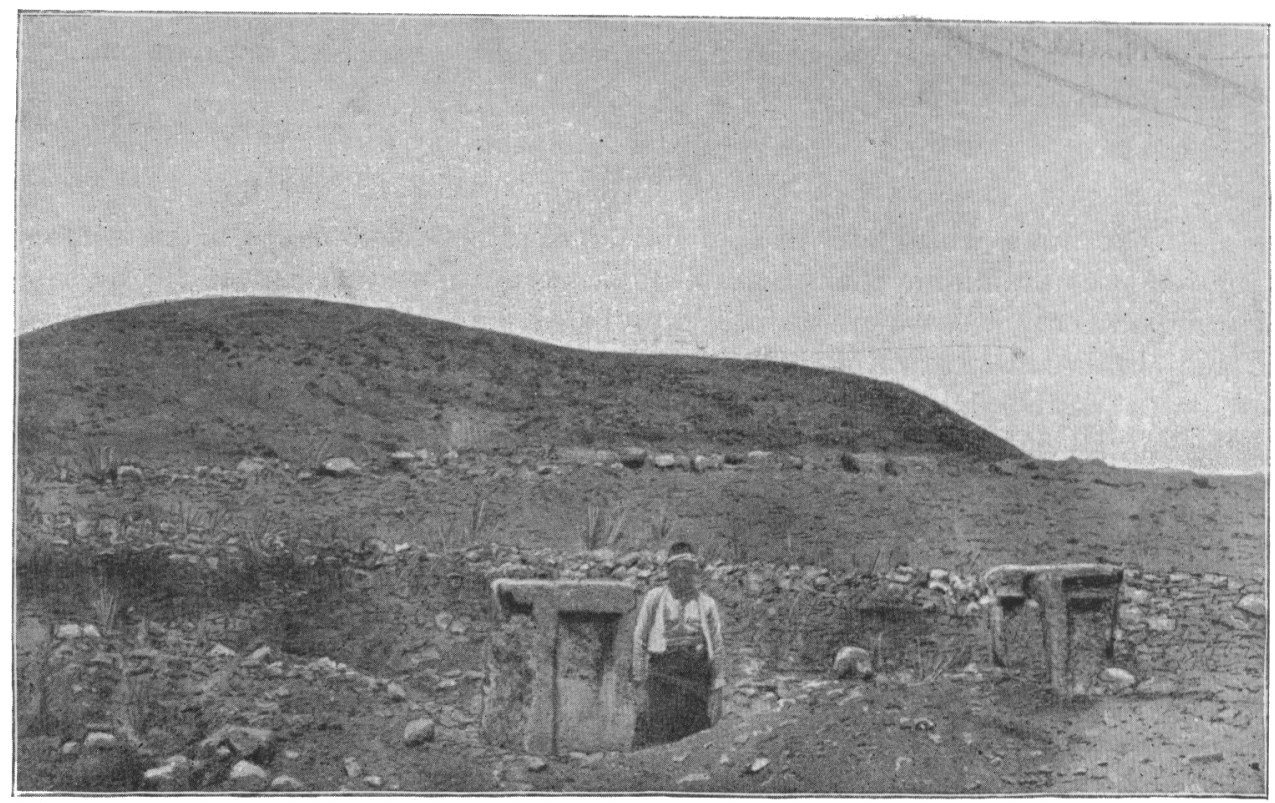

Fig. 2, - THE TEPE FRoM THE S.E. 


\section{Inscribed Pillar.}

The identity of this site with Lystra is fixed by the inscription on the pillar, which is a dedication to Augustus, its founder, by the colony. The inscription was discovered by Prof. Sterrett, who published it in the Wolfe Expedition, p. 142, cf. C.I.L., vol. iii. No. 6786. It was suggested by Prof. Ramsay (The Church in the Roman Empire, p. 51), on the analogy of a similar dedication to Augustus found in the temple of Artemis at Ephesus, that this stone marked the site of the temple of Z Z $\epsilon \dot{v} \varsigma \dot{o} \hat{\omega} \nu \pi \rho \dot{o} \tau \hat{\eta} \varsigma \pi \dot{\lambda} \lambda \epsilon \omega \varsigma$ (Acts xiv. 13). This suggestion may be right, but the removal of two or three feet of soil shewed that the stone was at all events not exactly in its original position. We found no traces of Roman work near it, or between it and the other pillar shewn in the photograph. The stones had been moved from their original position, which may or may not have been near, and had been used as the door-posts of a Turkish house, the foundations of which could be traced between the pillars and on either hand. The pillars measure respectively $4 \mathrm{ft} .11 \frac{1}{2}$ in. high by $2 \mathrm{ft} .7 \frac{1}{2}$ in. broad and $1 \mathrm{ft} .11 \frac{1}{2} \mathrm{in}$. deep and $4 \mathrm{ft} .5 \frac{1}{2}$ in. by $2 \mathrm{ft} .7 \mathrm{in}$. by $2 \mathrm{ft} .1$ in. The larger, which is on the right, is inscribed. The distance between the two stones is $9 \mathrm{ft} .5 \mathrm{in}$. The foundations of a small building $(A)$, which we examined on the east side of the tepé, proved to be those of a small Byzantine church. The annexed plan (Fig. 3) makes any further description of it unnecessary.

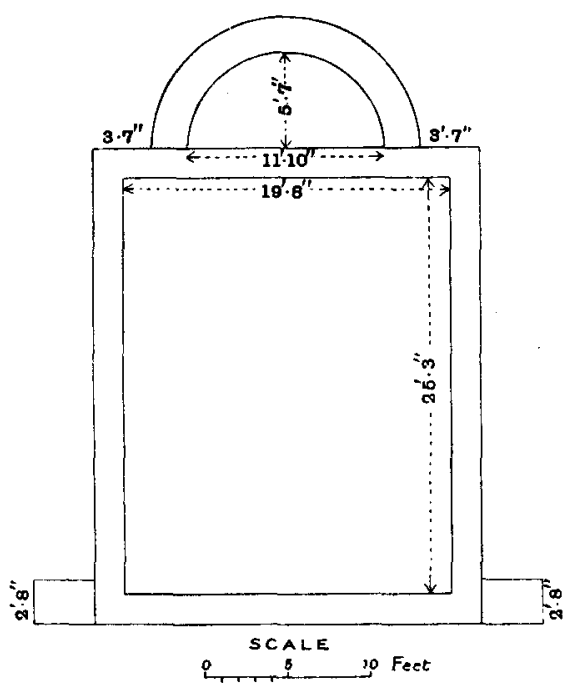

FIG. 3 


\section{The Site, Roman Road and Gate.}

It will be seen from the photograph and sketch that the tepé rises sharply from the plain on all sides, and that it is somewhat higher at the south end than at the north. In the centre of the south end there is a depression through which a road must have entered the city : a short distance from this depression, on the slope of the tepé south of its south-east comer, at the spot marked $C$, we were told that a gate had once stood. No traces of the gate could be seen above ground and, though we removed some of the soil, we could find no trace below ground of its foundations. The tradition is, however, worth putting on record; it came to us on the authority of an aged inhabitant of the village, who had seen it in his childhood. It appeared to us that the tradition might be true, for there was an incline along the face of the slope leading from the depression before alluded to, past the site assigned to the gate and round the south-east corner of the tepé. This incline was continued along the east side until it joined the plain, and was on the whole such as might mark the ancient course of a road. It is marked $B B B$ in the sketch.

H. S. Cronin. 